\title{
Significados da decisão do "retorno" para brasileiros/as com experiências migratórias na Inglaterra
}

\section{Meanings of the decision to "return" for Brazilians with migratory experience in England}

\section{Significados de la decisión de "retorno" para los brasileños/as con experiencia migratoria en Inglaterra}

\author{
Laila Priscila Graf Ornellas* \\ Universidade Federal de Santa Catarina - UFSC, Florianópolis, Santa Catarina, Brasil \\ Maria Chalfin Coutinho** \\ Universidade Federal de Santa Catarina - UFSC, Florianópolis, Santa Catarina, Brasil
}

\begin{abstract}
RESUMO
Apresentamos parte dos resultados de uma pesquisa sobre as trajetórias sociais de brasileiros/as com experiência migratória internacional, analisando os significados relativos à decisão do "retorno". Compreender a formação dessa decisão se mostra fundamental à medida que essa concretização é uma reelaboração do projeto de migrar, e redefine a situação e o contexto de vida da pessoa, dos familiares e de pessoas na sociedade de origem e destino. Empregamos um conceito de trajetórias sociais francês, e a teoria da psicologia construcionista social e dos estudos narrativos. Coletamos as informações a partir de entrevistas com oito pessoas, que residiram na Inglaterra por um ano ou mais e retornaram ao Brasil entre 2008 e 2012. A maioria desses participantes eram jovens e qualificados, praticamente todos com formação superior no Brasil. Entendemos o regresso dentro da totalidade da experiência migratória, no entanto aqui desenvolvemos uma análise transversal às trajetórias dos participantes. Eles optaram pelo retorno a partir de uma narrativa pessoal que foi construída a partir de um "mosaico" de fatores, contendo: a data prevista; inserção profissional anterior; questões familiares; crise econômica e falta de perspectivas no destino; e busca por determinada qualidade de vida.
\end{abstract}

Palavras-chave: trajetórias, narrativas, retorno, migração.

\begin{abstract}
We present here the research findings on labour trajectories of Brazilians through an international migratory experience, analysing the meanings of "return" built during the decision-making process. This research is based on a French conception of social trajectories, social constructionism, and narrative studies. Information was collected from ten participants who returned to Brazil between 2008 and 2012. This group was characterized as mostly young and with a higher-level of education in Brazil. The analysis of
\end{abstract}


the narratives led us to reiterate the need to consider the return within the totality of the migratory experience. The decision is based on a personal construction of a "mosaic" of relevant factors, with emphasis on these dimensions: visa expiration date, previous work contract, family issues, economic crisis, and lack of prospects in the destination, and search for quality of life.

Keywords: trajectories, narratives, return, migration.

\begin{abstract}
RESUMEN
Presentamos aquí algunos de los resultados de una encuesta sobre las trayectorias laborales de los/las brasileños/as con experiencia migratoria internacional, mediante el análisis de los significados de "retorno" construidos durante el proceso de toma de decisiones. Basamos esta investigación en una concepción francesa de las trayectorias sociales, el construccionismo social y los estudios narrativos. Recopilamos la información de diez participantes con retorno entre el 2008 y 2012, la mayoría joven, cualificada, y casi todos con la educación superior en Brasil. El análisis de las narraciones nos llevó a reiterar la necesidad de considerar el retorno dentro de la totalidad de la experiencia migratoria, y la decisión implicó la construcción personal de un "mosaico" de factores que son relevantes, con énfasis en estas dimensiones: expiración de visados, contrato de trabajo anterior, problemas la familia, la crisis económica y la falta de perspectivas en el destino y la búsqueda de la calidad de vida.
\end{abstract}

Palabras clave: trayectorias, narraciones, retorno, migración.

\title{
1 Introdução
}

Apresentamos neste artigo parte dos resultados de um estudo de doutoramento em psicologia sobre as trajetórias sociais de brasileiros/as com experiência migratória internacional ${ }^{1}$, analisando aqui os significados atribuídos à decisão de "retorno" 2 junto aos participantes que se estabeleceram na Inglaterra. Entendemos "significados" a partir de Tolfo, Coutinho, Baasch e Cugnier (2011). Esses autores, analisando esse termo em relação aos estudos do trabalho na psicologia, esclarecem que sentidos e significados são conceitos articulados; no entanto, os sentidos estariam mais associados aos processos singulares das pessoas, envolvendo uma análise detalhada de toda a história de vida dos sujeitos para entender como compreende determinada questão, e, por outro lado, os significados seriam mais relacionados a um entendimento coletivo (ou dos discursos) direcionado a um determinado aspecto ou sobre o "retorno", como ocorre aqui. Diante disso, neste artigo, apresentamos um recorte transversal, voltado aos discursos coletivos ou dos significados direcionados à construção da decisão do retorno e que perpassaram as trajetórias sociais dos participantes do estudo ${ }^{3}$. Os autores acima também assinalam que os sentidos/significados podem ser entendidos a partir de diferentes abordagens no âmbito da psicologia e, assim, empregamos a psicologia construcionista social para fundamentar o conceito assinalado. 
Neste estudo, desenvolvemos uma pesquisa qualitativa, tendo entrevistas como instrumento, e trabalhamos com oito brasileiros/as que viveram por um ano ou mais na Inglaterra e regressaram entre os anos de 2008 a 2012. Esses participantes eram em sua maioria jovens e qualificados, tendo a maioria concluído o ensino superior no Brasil antes do movimento migratório: quanto ao perfil, cinco eram mulheres e três homens, com a média de 31 anos de idade.

As migrações internacionais não são fenômenos recentes (Póvoa Neto, 2009). Elas ocorreram em diversos períodos no decorrer da história da humanidade e podem ser intimamente associadas a eventos globais significativos, tais como: revoluções, guerras, crescimento e o declínio de impérios, mudanças econômicas, expansões, construções de nações, transformações políticas, conflitos, perseguições, disposições de terras. Esses eventos foram motivadores de grandes deslocamentos humanos em diferentes partes do mundo.

Historicamente, o Brasil é um país que se constituiu por meio de deslocamentos e processos migratórios. Houve diversos movimentos que compuseram a história do país, como a imigração portuguesa, a população deslocada e escravizada negra, imigrantes alemães, italianos, japoneses, poloneses, entre outros. Frequentemente, no país, o termo migrante era relacionado ao entendimento de pessoas oriundas de outros países que vinham estabelecer-se no território brasileiro; em outras palavras, definiam a imigração. No entanto, a partir da década de 1980, outro fenômeno se evidenciou: um grande número de brasileiros/as, por diversos motivos, entre eles a busca de melhores condições de vida, deslocou-se para países de economia central, constituindo um movimento emigratório (Firmeza, 2007, Patarra, 2005).

Até a década de 1970, brasileiros iam para o exterior, mas era um grupo com grande poder aquisitivo e numericamente inexpressivo. Somente nos anos 1980 que a emigração de brasileiros/as foi ampliada. Martes (2001) esclarece que 1,5 milhão de pessoas deixaram o Brasil, o que foi significativo porque mostrou um movimento migratório diferente da tradição imigratória consolidada no país. Nas décadas seguintes, no Brasil ficaram coexistindo movimentos imigratórios, com a entrada de pessoas com um perfil mais variado, e emigratórios, com brasileiros/as se deslocando para diversas partes do mundo; primeiramente, o principal destino era para os Estados Unidos e, posteriormente, após atentados de 11 de setembro de 2001, com aumento do controle das fronteiras, para a Europa sobretudo (Assis, 2008; Pereira e Siqueira, 2013).

Em um contexto bem mais recente, a partir de 2008, foi possível observar melhoras em termos econômicos e sociais e decréscimo das taxas de desemprego no Brasil. Segundo informações da Pesquisa Mensal de Emprego (PME) do Instituto Brasileiro de Geografia e 
Estatística (IBGE), a taxa de desemprego decresceu entre 2008 a 2012 a $6,2 \%$, sendo que em 2014 e 2015 as taxas estavam em torno de $5,7 \%$ e 5,0\%, respectivamente. Com essa modificação do contexto socioeconômico e, por outro lado, os Estados Unidos e outros países de economia central sofrerem ainda as consequências da crise financeira instaurada no final de 2006 e 2007 (Siqueira, 2009), muitos brasileiros/as emigrantes decidiram regressar ao Brasil.

O movimento de retorno sempre existiu no contexto das migrações internacionais, no entanto houve um acréscimo registrado em 2010. No Censo de 2010, houve o registro de mais de 174 mil brasileiros que anteriormente residiam no exterior por um período maior de cinco anos (IBGE, 2012), sendo 86,7\% maior do que o número encontrado no Censo de 2000. Diante disso, este artigo enfoca esse período em que houve um acréscimo dos retornos de emigrantes brasileiros/as ${ }^{4}$.

$\mathrm{Na}$ pesquisa original (Autora, 2015), identificamos diferentes elementos fundamentais e com necessidade de serem destacados na análise das trajetórias sociais dos emigrantes retornados investigados, pois as trajetórias sociais se mostram riquíssimas para compreender os processos de migrar, viver e trabalhar. Contudo, 0 recorte analítico desenvolvido aqui foi de caráter transversal, ou seja, voltado às análises das construções narrativas associadas à decisão de regressar ao país de origem.

Compreender as narrativas anteriores ao retorno é importante porque se referem às ideias que circulavam na vida dos participantes na época e impulsionaram a modificação na trajetória de suas vidas, nos seus cotidianos, de seus familiares e de outras pessoas da sociedade de origem e destino. Segundo Siqueira (2009), para algumas pessoas o retorno à terra natal é mais difícil do que o ato de emigrar, por envolver estranhamentos com a família de origem, dos costumes, não reconhecimento de pertencer ao lugar e diversas mudanças.

Mesmo que o retorno não seja definitivo, podendo a pessoa voltar a emigrar, ele é vivido como decisivo. Retornar é mais que mudar de residência, é juntar todos os pertences, encaixotar e despachar, é despedir-se sem perspectiva de voltar a rever brevemente, deixar uma vida e projetar construir outra no país de origem, reencontrando pessoas e lugares, mas que passaram por modificações durante 0 tempo de ausência. Ou seja, do ponto de vista da experiência individual, nesse processo há uma redefinição de territorialidades, como expressam Marandola Jr. e Dal Gallo (2010), pois há uma exigência de que a pessoa desenvolva novos entrelaçamentos com o mundo social para produzir seu pertencer, sendo um processo que pode trazer dificuldades, haja vista as situações conhecidas/desconhecidas a serem enfrentadas, que podem desestabilizar a pessoa em relação à sua segurança pessoal. No 
retorno, os emigrantes precisam reconstruir o seu pertencer na cidade de origem e desenvolver novas inter-relações com os espaços e com as pessoas.

A psicologia construcionista social se mostra relevante para compreender esses discursos que permeiam o retorno por procurar entender os sujeitos por meio das significações construídas social e historicamente, sem determinações essencialistas. Com essa abordagem, é possível desenvolver recortes analíticos que compreendam os discursos sociais, bem como as apropriações deles.

Assim, para sustentar as análises desenvolvidas aqui, apresentamos as concepções teóricas das trajetórias sociais, do construcionismo social e das narrativas, como também a noção de retorno a partir de Sayad $(2000 ; 1998)$. Em seguida, esclarecemos os procedimentos de método, incluindo as características dos participantes, procedimentos de coleta e análise das informações, e, por fim, os resultados.

\subsection{Trajetórias sociais}

O estudo das trajetórias sociais permite compreender diversos aspectos da vida das pessoas, a partir de suas histórias/estórias de vida ${ }^{5}$. São múltiplas as possibilidades e enfoque de análise. Por exemplo, em relação à dimensão do trabalho, podemos compreender como foram construídos os percursos laborais, as inserções profissionais, primeiros empregos ou trabalhos, relações de trabalho, escolhas profissionais e de carreira, cotidiano do trabalho. Como também, diante do contexto migratório, podemos analisar os movimentos de deslocamentos das pessoas entre os países e identificar os motivos, significados dos percursos e cotidiano.

Existem diversos modos de compreender trajetória. Neste estudo, entendemos as trajetórias como um modo de investigar a movimentação das pessoas em um determinado período de tempo, sendo possível efetuar uma compreensão biográfica pessoal articulada com a história e espaços sociais (Moya \& Escudero, 2005), além de compreender, por meio das trajetórias, os modos de inserção laboral, empregos, rendimentos, entre outros.

Quanto à definição do conceito de trajetórias sociais, empregamos as ideias de Dubar (1998). Para o francês, a análise das trajetórias sociais necessita ser desenvolvida a partir da integração de uma dupla compreensão: das "trajetórias objetivas" e das "trajetórias subjetivas" ou "biográficas" (Dubar, 1998). As primeiras se caracterizam pelas sequências de posições dos sujeitos em um ou mais campos da prática social, como percurso e as posições das pessoas durante a vida escolar ou profissional, observando elementos comuns nos itinerários dos sujeitos e analisando-os objetivamente. Por outro lado, as trajetórias subjetivas estariam relacionadas às 
narrativas sobre a biografia pessoal; em outras palavras, seriam os entendimentos da pessoa sobre fatos cotidianos da sua vida.

Dubar (1998) entende a identidade singular humana a partir de uma perspectiva relacional. Ou seja, a identidade não seria relacionada a algum tipo de essência ou a traços de caráter, tampouco o ser humano seria considerado uma ilusão ou atrelado a elementos da estrutura social. O autor, com base nessa perspectiva relacional, considera os processos de categorização na construção das identidades individuais, evidenciando uma noção de identidade que propõe articular os quadros sociais de identificação juntamente com os discursos individuais. Isso corresponde a uma ideia de identidade como resultado da articulação de dois processos: no primeiro estariam os elementos sociais de identificação, ou seja, o enquadre social da pessoa nos grupos e na sociedade (gênero, cor, etnia, camada social, cidade de origem, bairro). No segundo processo estariam os elementos produzidos pelo discurso das pessoas sobre elas mesmas (como ela se entende).

Essa dupla dimensão da identidade pode ser investigada por meio das trajetórias sociais, conforme salienta Dubar (1998), considerando tanto o social quanto os discursos da pessoa. Esse entendimento das trajetórias pode viabilizar conhecimentos substanciais das pessoas diante de processos migratórios, pois pode proporcionar um entendimento identitário dos sujeitos migrantes, com uma compreensão social e local, como assinalaram Moya e Escudero (2005), mas também pesquisando a dimensão identitária, conforme Dubar (1998), nas mudanças sociais e culturais ocasionadas pela migração.

\subsection{Noção de Retorno}

Buscando compreender o deslocamento de regresso ao Brasil, apresentamos a noção de retorno de Sayad $(2000,1998)$. Segundo o autor, para existir um regresso ao país de origem, houve diversos movimentos anteriores que constituíram a pessoa como um migrante internacional. Entre eles, está a decisão de migrar, conhecer, ingressar no país estrangeiro, residir no destino, trabalhar, viver no cotidiano, entre outros processos. Sayad (1998) esclarece que o processo de imigração não pode ser pensado descolado do processo de emigração, sendo que os dois processos são constitutivos das vidas dos migrantes. Para a pessoa partir, em algum momento foi preciso deixar um território anterior, pessoas, lugares e referências e, dessa forma, tentar, do modo que lhes for possível, construir novos referenciais nesse novo e desconhecido lugar. Diante disso, 0 processo de deslocamento internacional poderia ser analisado a partir de variados recortes, mas sempre considerando o processo de forma 
integral. Assim, pelos limites do artigo, enfocaremos mais especificamente o movimento de retorno.

A Organização das Nações Unidas (ONU) define os migrantes retornados (returning migrants) como pessoas que estão "retornando ao seu país nacional após terem sido migrantes internacionais (independente de se de curta duração ou de longa duração) em outro país e objetivam permanecer em seus próprios países pelo menos um ano" (tradução livre, United Nation, 1998, p. 95). Portanto, é necessário a pessoa ter efetuado no mínimo dois movimentos, partida e regresso, assumindo com isso todas as mudanças que esses dois processos envolvem, os quais são se estabelecer nesses lugares, procurar uma moradia, trabalho, ambientar-se com a localidade, entre outros.

Analisando o retorno, Sayad (2000) esclarece que não se habita um outro país impunemente. Entre muitos fatores, o tempo transcorre para todos, tanto para aqueles que migram como para aqueles que ficam. Segundo o autor, muitas pessoas pensam que na volta irão encontrar as pessoas, os eventos ou os locais como eram anteriormente e se enganam, pois todos se transformam com 0 tempo. Sayad (2000) apresenta a ideia da "dor do retorno" como a descoberta que o retorno não é solução dos problemas enfrentados, porque, segundo ele, mesmo sendo possível a pessoa voltar ao mesmo ponto de partida, pois o espaço aceita esse tipo de movimento, não é possível que ela volte ao mesmo tempo ou que encontre a mesma situação deixada. Essa dor é compreender o inexistir do "lugar" imaginado. Heráclito, como mencionou Sayad (2000), indicou ser impossível atravessar o mesmo rio duas vezes, pela correnteza da água; os lugares do retorno são também transformados, por isso, em outras palavras, inexiste um verdadeiro retorno.

\section{Procedimentos de pesquisa}

Adotamos nesta pesquisa um enfoque qualitativo de investigação. Creswell (2003) esclarece que a perspectiva qualitativa procura entender as experiências e os sentidos produzidos pelas pessoas direcionados a certos objetos ou fenômenos. Esses sentidos produzidos sobre determinados objetos são variados e múltiplos. Assim, o investigador precisa de um olhar atento para identificar essas relações de complexidades. Também empregamos na pesquisa o suporte teórico e metodológico da psicologia construcionista social. Burr (1995) esclarece que essa teoria atua de uma maneira crítica em relação aos modos de compreender o mundo, questionando os entendimentos "naturais" ou "dados" (taken-for-granted), e nos convida a observar o "mundo" entrelaçado e produzido pelo social. 
Com essa base, os pesquisadores são alertados para suspeitar de suas próprias verdades construídas e tomadas como "naturais", pois os estudos visam a problematizar as crenças mais incontestáveis estabelecidas pelas pessoas em geral e pela sociedade. $O$ construcionismo social difere dos paradigmas tradicionais da pesquisa científica, por compreender o "mundo" como relacional e não concordar com uma objetividade absoluta.

Segundo Gergen (1999/2009), as pesquisas nessa abordagem possuem um formato mais flexível, com base em exemplos e argumentação. Entre os modos de investigação, estaria o estudo das narrativas de conteúdo, sendo que esse modelo destaca os desafios presentes na vida de pessoas por meio do conhecimento público. Riessman (2008) indica o conceito de narrativa como uma atividade cotidiana de contar uma estória ou um conto, mas observando os modos como a pessoa conecta os eventos em uma sequência específica, direciona a fala voltada a um público específico e indica consequências para uma ação posterior. O conteúdo das narrativas pode ser vivências passadas, lembranças, sentimentos, reflexões passadas e atuais, porém eles objetivam direcionar o interlocutor para um propósito atual.

Empregamos a entrevista como instrumento de pesquisa, dentro desse entendimento de narrativas (Riessman, 2008), e trabalhamos a entrevista em duas partes: na primeira, seguimos com roteiro para levantar as informações referentes aos dados pessoais, objetivos e períodos migratórios, educação, trabalho, família. Na segunda parte, aplicamos a Técnica de Trajetórias Sociais (TTS), em uma versão desenvolvida pelos autores a partir do trabalho de Gaulejac (1987), que consiste na produção gráfica de uma linha de vida, na descrição de eventos significativos e na narração posterior sobre ela.

Os participantes deste estudo foram oito pessoas que residiram por um ano ou mais na Inglaterra e retornaram ao Brasil entre 2008 a 2012. Eram cinco mulheres e três homens. Seis deles residiram em Londres, capital, e dois em cidade do interior. A idade média era de 31 anos, sendo a mínima 26 e a máxima 49 anos. Quanto aos documentos de entrada na Inglaterra, dois deles possuíam o visto de trabalho, dois tinham dupla nacionalidade, três tinham visto de estudante e um estava sem documento. As entrevistas com os participantes ocorreram entre maio a setembro de 2012.

Para a análise das informações, transcrevemos todo o material gerado com as entrevistas. Efetuamos as análises em duas etapas, a primeira desenhando o perfil do participante, inspirados parcialmente em Dubar (1998), e, posteriormente, com apoio teórico das narrativas temáticas de Riessman (2008) e do trabalho de Gee (1991), desenvolvemos uma categorização de todas as narrativas presentes nos discursos dos participantes. Essa foi uma análise transversal das histórias dos participantes, a qual gerou eixos 
narrativos sobre acontecimentos na partida, no destino e no retorno. Aqui tratamos das narrativas geradas no eixo narrativo do "retorno" e, mais especificamente, sobre "a decisão de retornar".

\section{Narrativas sobre os retornos}

Como assinalamos com Sayad (2000), não existe verdadeiramente um retorno, pois, mesmo que o espaço aceite esse movimento, não é possível voltar e, ao mesmo tempo, encontrar a mesma situação deixada. O retorno pode até ser anunciado como "uma volta ao país de origem", contudo isso não ocorre na experiência pessoal. Diante desses entendimentos, enfocamos as narrativas de retorno dos entrevistados. Seus relatos foram permeados por reflexões e pensamentos sobre a decisão de retornar. Eles levaram em consideração diferentes aspectos sobre suas vidas sem haver apenas um único "motivo", mas sim uma formação de significados que corresponderia a um "mosaico" de fatores.

Um primeiro ponto a considerar foi o fato de nenhum dos oito entrevistados ter regressado por meio de uma remoção administrativa (comumente chamada de deportação). De acordo com Blinder (2014), no ano de 2013, somente no Reino Unido, 50.741 mil pessoas foram removidas ou deixaram o país após um processo inicializado de remoção. Segundo o autor, esse número cresceu em $14,5 \%$ em relação ao número em 2012 . Os números mostrados por Blinder (2014) expressam tanto a recorrência de remoção feita pelos setores da administração pública quanto um acréscimo de processos efetuados naquele país entre os anos de 2010 a 2013.

Diante desse contexto, cabe ressaltar nossa preocupação em levantar os significados produzidos pelos participantes sobre a tomada de decisão do processo de retorno. As significações não podem ser entendidas como elaboradas exclusivamente pela pessoa, pois são sempre construídas por meio da participação no coletivo em um contexto histórico e social específico, com fatores que interpelam os sujeitos e também integram a decisão pessoal. Com isso, na análise das narrativas dos participantes, identificamos cinco construções narrativas sobre o regresso: a) expiração do visto de estudante; b) inserção laboral antes do retorno; c) questões familiares; d) crise e falta de perspectivas; e) busca por determinada qualidade de vida.

\subsection{Retorno com data prevista}

Identificamos, nas narrativas de três entrevistados, o retorno como estreitamente relacionado à expiração do visto de estudante. Para Guilherme, Danuza e Heloísa ${ }^{6}$, a data estabelecida previamente no passaporte, no visto de admissão ao país de destino, foi a data limite 
para permanecer na Inglaterra. Embora os três participantes tenham acatado o prazo determinado pelo consulado, isso não correspondia diretamente às expectativas pessoais e projetos que esses participantes possuíam para suas vidas. Por exemplo, Guilherme relatou sua dificuldade quanto ao retorno, salientando que, se essa escolha dependesse dele, ele não retornaria.

Nenhuma; por mim, eu ficava lá, só voltei por causa do visto. No momento do retorno, foi legal ver a família, matar a saudade, mas o problema estava no emprego, tudo difícil; eu achava que seria difícil de novo. Eu adoro o frio, sinto muita falta de Londres, sinto muita falta de lá. Eu estava vendo as fotos, e fico com vontade de estar lá (Guilherme).

Helena relatou ter ponderado sobre diferentes vivências antes da expiração do visto de estudante, tanto na Inglaterra como no Brasil. Segundo ela, as dificuldades em ser, ao mesmo tempo, trabalhadora e estudante naquele país estavam aumentando. A carga horária autorizada para o trabalho de estudantes estava sendo reduzida, passando de vinte horas semanais para dez horas de trabalho regulamentado. Também houve o aumento do controle e das exigências para a renovação do visto. Por outro lado, com mais tempo no exterior, ela enfrentaria dificuldades para reingressar no trabalho no Brasil, em que era concursada e tinha licença sem vencimento. $\mathrm{O}$ momento de retorno e o período anterior de decisão foi intenso e sofrido, mesmo tendo a limitação de data de autorização para residir em Londres.

Fiquei lá um ano e, no final, eu fiquei em dúvida se ficava mais um, e acabei decidindo voltar [...]. Eu vim chorando de lá até aqui, de arrependimento. De não saber se estava fazendo a coisa certa, mas, por outro lado, imaginei que seria a coisa certa, pois lá chegou uma época em que eu não estava mais gostando do trabalho. Todo mundo te explorava pelo fato de você ser brasileiro e estudante (Helena).

Pereira e Siqueira (2013) identificaram um tipo de retorno por data estabelecida chamado pelas autoras de "retorno planejado de estudantes", que caracterizaram como um projeto migratório de curto ou médio prazo, correspondendo ao período de estudo no país de destino, como no caso de um estudante com bolsa de doutorado na modalidade sanduíche. Para as autoras, os projetos migratórios dessas pessoas eram bem delimitados e também eram concretizados dessa maneira. Porém, os participantes do presente estudo se diferenciam daqueles por dois motivos. Primeiro, por esses estudantes estarem matriculados em cursos complementares como o 
de idioma, com financiamento próprio ou familiar, diferentemente de um curso de elevada qualificação, como um doutorado e com financiamento público. O segundo é que, além de estudantes, eles eram trabalhadores. Assim, os participantes aqui poderiam ser duplamente qualificados; não eram apenas estudantes, mas sim correspondiam a migrantes "trabalhadores-estudantes".

Uma discussão sobre "trabalhador-estudante" auxilia no desdobrar dessa dupla qualificação dos participantes aqui descritos. D'Avila (2014), com base nos estudos de Foracchi (1977), elaborou uma discussão voltada para o contexto do ensino superior. D'Avila (2014) esclarece que na contemporaneidade há possibilidade de as pessoas conjugarem o trabalho e o estudo, sendo que essa conciliação ocorre porque existe o trabalho parcial, como cursos de graduação noturnos e de meio período. Para a autora, porém, essa dinâmica de agregar atividades apresenta características peculiares, pois ambas as atividades são exigentes em termos de empenho e dedicação. Nessa compreensão, há o "estudante-trabalhador", cuja atividade laboral seria considerada complementar ao estudo, como também o "trabalhador-estudante", em que o principal papel seria ser trabalhador 0 do estudante secundário ou complementar. Considerando essas duas modalidades, pudemos identificar os entrevistados da presente pesquisa como "trabalhadores-estudantes", pois trabalho era fundamental para sua manutenção no país de destino. Diante disso, eles estariam distantes da condição exclusiva de "estudantes" ingressando no país de destino para dedicação exclusiva às atividades acadêmicas, mesmo contando com essa descrição em seus documentos migratórios.

Os "trabalhadores-estudantes" entrevistados atuavam em atividades laborais não diretamente relacionadas aos seus estudos, elas eram frequentemente no setor de serviços e exigiam esforço físico ou manual. Trabalhadores nesses tipos de serviços são chamados de colarinho azul (blue-collars workers). Schreurs et al. (2011) salientam que os trabalhadores de colarinho azul atuam mais frequentemente sobre os objetos que são tangíveis, como substâncias ou materiais, ferramentas, equipamentos ou produtos, diferentemente dos de colarinho branco (white-collar workers), que lidam mais com informação, com números, símbolos, ideias, conceitos e conhecimento.

Dessa forma, cabe destacar que parte dos participantes desta pesquisa era composta por trabalhadores-estudantes, exercendo atividades laborais predominantes no setor de serviços e em atividades com exigência de trabalho físico. Eles tinham uma data de retorno, no entanto seus projetos não eram delimitados, pois, se eles tivessem condições de permanecer, possivelmente ficariam por mais tempo naqueles países, como foi evidenciado na fala de Guilherme e pela indecisão de Helena. Diante de dificuldades relacionadas à 
permanência no destino, essas pessoas optaram por retornar na data prevista, embora essa "escolha" pudesse ser significada mais como um impedimento em permanecer do que uma opção. Para esses entrevistados, diante desse retorno "previsto" e desse contexto migratório, o processo da "volta para a casa" não ocorreu tranquilamente. As diferenças de residir em outro lugar e ter construído novos hábitos foram significativamente sentidas pelo migrante e familiares. Danuza relata essa dificuldade no ambiente familiar.

Então, eu voltei na data que estava prevista para eu voltar mesmo, um ano depois. Foi um choque. Porque eu estava acostumada num ritmo de vida diferente e morando sozinha, e na volta eu voltei a morar com os meus pais. Então, para todos foi um período de adaptação um pouco difícil, assim... Especialmente nos dois primeiros meses, tivemos vários conflitos aqui em casa. Então, eu estava acostumada a ficar sem dar satisfação a ninguém, vou aonde eu quero, a hora em que eu quero, eu volto, porém, quando tu voltas a morar com os pais, não é assim que funciona. E eu mesma voltei diferente; morar fora muda a cabeça, o jeito que você pensa, então é toda uma readaptação (Danuza).

Diante da condição desses entrevistados, a possibilidade de permanecer no país de destino, naquele momento, de forma apropriada e documentada, não estava presente. Veiner (2007) esclarece que o laisser-passer da modernidade madura é seletivo, visto que significativa quantidade de pessoas não possui acesso a essa liberdade de ir e vir: alguns são proibidos de entrar e outros são proibidos de ficar, como os participantes aqui entrevistados. Desse modo, parte dos entrevistados foi impedida de permanecer no destino pelo prazo estipulado pela concessão do visto. Isso não correspondia ao projeto deles, mas acataram a decisão e o limite estabelecido no passaporte.

\subsection{Retorno com inserção profissional anterior}

A inserção profissional antes do retorno foi especialmente relevante nas narrativas de dois participantes: Amanda e Pedro. Ambos conseguiram uma inserção profissional antes do retorno ao Brasil. Pedro estava pesquisando oportunidades (ou a falta) de crescimento profissional na Inglaterra e mudança de emprego. Também tinha vindo de férias ao Brasil e pensando em regressar.

Eu vim para cá em 2011; de 2010 para 2011, eu vim para cá de férias, aí eu conheci uma moça, de que eu gostei bastante, 
e ela falou: "Ah, se você quiser mesmo voltar para o Brasil, você deve pensar em alguma coisa", e eu comecei a pensar e aquela coisa bateu e comecei a pensar. Coincidentemente, nessa empresa do Brasil, eles lançaram uma vaga para cargo de gerente, para o qual eu não fui selecionado, e logo eles lançaram uma vaga para o cargo de coordenador, para o qual fui selecionado. [...]. O processo seletivo foi todo por webconference. Dessa vez, eu não vim para cá para fazer a entrevista no Brasil e acho que se tivesse vindo eu provavelmente não teria aceito a vaga (Pedro).

Amanda também foi contratada antes de regressar. Ela relatou ter observado à época um contexto marcado por dificuldades econômicas no país de destino e, consequentemente, menores possibilidades de contratação e rendimentos, mas, por outro lado, o Brasil estava em uma situação de ascensão social e econômica. Ela identificou uma oportunidade, foi selecionada e contratada pela instituição. Como é possível observar no relato de Amanda, o contrato com a organização não foi o único motivo de regresso; o familiar estava presente do mesmo modo, mas esse fator gerou o regresso.

Ah, eu sempre me adaptei muito bem à Inglaterra. Eu não queria voltar; eu estava muito adaptada. Se eu não tivesse tido filho, eu não teria voltado. Eu gostava muito de morar na Europa, gostava muito do ambiente de trabalho, enfim, mas eu pensava bastante na questão de, enfim, ela ter contato com a família, da [filha] crescer perto da família, de eu poder ter uma ajuda maior da minha mãe principalmente e também tinha algumas coisas da crise financeira em que a Inglaterra estava entrando. Isso contribuiu bastante [...]. Eu disse: "Ah, daqui a pouco essa verba reduz e daqui a pouco estou sem contrato aqui e perdi essa oportunidade em um lugar que eu sabia que era, enfim, era na minha cidade, não é?" (Amanda).

Para esses dois entrevistados, os significados atribuídos ao retorno envolveram uma oportunidade relacionada à inserção profissional, embora com outros fatores. O contrato de trabalho antes de retornar foi um viabilizador nesse processo. No caso de Amanda, o trabalho viabilizou a sua mudança, como da sua família. Contudo, mesmo com esse vínculo antes do regresso, pudemos observar também a ocorrência de estranhamentos quanto à volta ao país de origem. Como assinalado por Sayad (2000), essa volta não foi uma "retomada" da vida anterior, mas sim um novo começo. 


\subsection{Questões familiares}

Os participantes também destacaram a família como um fator prioritário para o regresso. Gabriel voltou da Espanha para auxiliar a família. Estrella Vega (2013) também identificou esse aspecto em relação a mulheres retornadas, não deportadas; as entrevistadas esclareceram que uma das razões de retornar estava relacionada com suas famílias ou para reencontrarem com seus familiares. Pereira e Siqueira (2013), em estudo com brasileiros retornados da Europa, identificaram um retorno chamado de "retorno antecipado por motivos familiares", ocorrendo particularmente em situações de separação ou da necessidade de apoiar familiares em períodos de doença no país de origem.

Eu voltei porque meu pai estava doente na época. Eu voltei para cuidar dele, em 2009, e voltei para cuidar e fiquei literalmente cuidando dele de fevereiro a novembro, que foi quando ele faleceu. Depois, quando isso aconteceu, eu fui tirar umas férias para reorganizar a cabeça, pois nesse tempo eu fiquei praticamente sem sair de casa para nada, nem saía para me divertir e nem nada, depois fiquei um tempo com minha mãe. Foi quando recebi essa oportunidade de trabalho que foi graças ao espanhol (Gabriel).

Outros entrevistados também relataram a importância de suas famílias quanto à decisão. Amanda e Camile a salientaram porque, no retorno, elas poderiam estar mais próximas dos seus familiares. Camile poderia estar mais próxima da filha, Amanda mais próxima de sua mãe. Pereira e Siqueira (2013) salientam que a dimensão familiar do retorno tem sido insuficientemente explorada na literatura, embora ela seja considerada importante e reconhecida nos estudos com brasileiros nos Estados Unidos.

\subsection{Crise econômica e falta de perspectiva no país de destino}

A crise e a falta de perspectivas estiveram presentes nas narrativas de praticamente todos os participantes, no entanto apresentaram-se mais evidentes com Camile. A Inglaterra não sofreu com um índice de desemprego tão acentuado, como ocorreu na Espanha (Moreno Fuentes e Ferreira, 2013), por exemplo, mas também teve uma elevação na taxa em comparação com os anos anteriores, com 7,9\% da população (Eurostat, 2012).

Eu retornei porque minha filha não queria ir para lá, pois ela estava com medo; a crise estava chegando ao país, já era final de 2010, começo de 2011. Eu voltei em 10 de dezembro de 
2010, quando começou a crise europeia, pois estava ficando mais caro para morar e aumentado, e ela me disse: "Mãe, estão deportando muito". Estava passando na televisão: estavam deportando até para chegar lá, perguntando o que iriam fazer e tal; ela não queria ir e eu já estava muito tempo fora [...]. A libra não compensava mais, estava $R \$ 2,70$ ou $R \$$ 2,45 , aí era muito pouco e aqui eu tenho minha casa. Eu voltei mais por causa da crise europeia. Depois, eles já foram pegando os que estavam ilegais (Camile).

\subsection{Busca por determinada qualidade de vida}

Apenas uma entrevistada citou o retorno associado à qualidade de vida. Para Ana, o retorno envolvia a qualidade de vida. Essa qualidade citada por ela foi relacionada a uma mudança nos modos de viver a longo prazo, com maior contato com a natureza, mudança de clima para temperaturas mais elevadas. Ela tinha um trabalho com estabilidade, em um hospital, e seu marido também tinha um emprego fixo como policial.

[...] Não vejo muita qualidade de vida, sabe? Porque eu gosto muito de ar livre e tal, e não gosto de sair, beber e comer durante seis ou sete meses por ano, porque é isso que você faz quando está frio ou chovendo. Daí ele [marido] gostou da ideia, pulou nela, sabe? Ele pegou carona na minha ideia, se empolgou e daí a gente não pensou mais; foi fazendo planos de como voltar e foi isso. Daí a gente veio, vendeu o que tinha lá e viemos esperando que fosse dar certo (Ana).

Clima e temperatura mais elevados, contexto familiar, tudo isso pode ser considerado como fatores relacionados a essa melhora de vida. Estrella Vega (2013) afirma, em seu estudo com mulheres retornadas dos Estados Unidos para El Salvador, que o retorno é um projeto sempre possível entre os migrantes, pois a experiência migratória é uma forma de colocar em jogo o sentido de pertencimento a uma comunidade. Ao mesmo tempo em que é um termômetro que serve para considerar os laços que unem os migrantes aos seus lugares de origem.

\section{Considerações finais}

Este artigo apresentou uma análise sobre a decisão de "retorno" transversal às trajetórias sociais dos participantes do estudo e objetivou desvelar discursos que subsidiaram a decisão dos participantes, os quais modificaram o curso de vida deles, e se 
constituem em escolhas pessoais cujos significados reverberam um momento histórico e social específico no Brasil e no exterior.

Para os aqui entrevistados, a decisão do retorno foi elaborada a partir das suas condições, das vivências e dos pensamentos, envolvendo relacionamentos no Brasil e na Inglaterra. Contudo, essas reflexões sobre o retorno nem sempre abarcaram a extensão e complexidade causada por esse deslocamento. Quando a pessoa migra, prepara-se para encontrar o novo, mas, quando retorna, nem sempre realiza essa preparação, pois retornar seria como voltar ao mesmo. 0 regresso não é um movimento que pode ser caracterizado como definitivo, pois, por mais que os participantes tenham regressado, poderão reemigrar, tal como mencionado por Siqueira (2009). Com isso, cabe também assinalar que as trajetórias sociais são construídas continuadamente, sendo que suas direções são definidas e redefinidas durante o percurso.

Entre as contribuições desse trabalho, temos, por um lado, o foco na emigração de retorno. Siqueira (2009, p. 87) esclarece que "[...] o projeto de migrar é social, familiar e coletivo e nele está incluído o retorno; contudo, a partir das diferentes trajetórias dos migrantes, ele vai sendo reelaborado [...]". Com este estudo, buscamos mostrar a complexidade e as dificuldades de construir essa reelaboração do projeto migratório para quem retorna, com desdobramentos para familiares e amigos envolvidos. A construção da decisão final e a concretude da ação foram vivenciadas pelos participantes com elevada carga de sofrimento, existindo nas narrativas indicações frequentes de sentimentos de angústia e ansiedade. Dessa forma, o "retorno" é um momento de grande exigência em termos pessoais, pois, mesmo sendo considerado uma "volta" ao lugar conhecido, uma ideia já desmistificada por Sayad (2000), a pessoa necessita novamente recriar lugares de pertencimento. Por outro lado, este estudo contribui no âmbito da psicologia em primeiro lugar por enfocar a migração de retorno, um tema insuficientemente explorado nesse campo do conhecimento, especialmente quanto a brasileiros e no Brasil. Em segundo, por empregar a psicologia construcionista social para as análises e, assim, desvelar as construções discursivas dos participantes sobre o tema.

Diante da complexidade do estudo das migrações de retorno, consideramos importante atentar para outras questões que não puderam ser abarcadas no recorte de pesquisa aqui apresentado. Algumas delas foram discutidas no estudo original, como os processos anteriores à decisão de retornar - o planejamento da partida e as vivências durante a estadia no estrangeiro - e as perspectivas futuras (Ornellas, 2015). Entre as questões relevantes a serem investigadas em futuros estudos, estariam aquelas relacionadas ao mapeamento dos sentimentos gerados com processo migratório de retorno, por meio de estudos com recortes longitudinais 
e da investigação sobre o sofrimento psíquico associado à experiência de retornar. Assim, consideramos como uma importante direção futura investigar as articulações entre sofrimento mental e a emigração brasileira de retorno.

\section{Referências}

Assis, G. de O. (2008). A fronteira México-Estados Unidos: entre o sonho e o pesadelo - as experiências de e/imigrantes em viagens não-autorizadas no mundo global. Cadernos Pagu, $3(0), 219-250$.

Blinder, S. (2014). Deportations, Removals and Voluntary Departures from the UK. Migration Observatory briefing, COMPAS, University of Oxford, UK, June. Recuperado de http://www.migrationobservatory.ox.ac.uk/documents/briefingdeportations-removals-and-voluntary-departures-uk

Burr, V. (1995). Social Constructionism. (2a. ed.). London; New York: Routledge.

Creswell, J. W. (2003). Research Design: Qualitative, Quantitative and Mixed Methods. (2a. ed.). Thousand Oaks; London; New Delhi: SAGE Publications.

D 'Avila, G. T. (2014). Movimentos laborais e sentidos atribuídos ao trabalho por jovens profissionais. Tese de Doutorado, Programa de Pós-Graduação em Psicologia, Universidade Federal de Santa Catarina, Florianópolis, SC.

Dubar, C. (1998). Trajetórias sociais e formas identitárias: alguns esclarecimentos conceituais e metodológicos. Educação \& Sociedade, 19(62), 13-30.

Estrella Vega, M. Y. (2013). Con la esperanza de volver: mujeres migrantes de retorno a El Salvador. Anuário Americanista Europeu, (pp. 165-177), n. 11, 2013.

Eurostat (2012). Unemployment statistic 2002-2013. Disponível em: http://ec.europa.eu/eurostat

Firmeza, G. T. (2007). Brasileiros no exterior. Brasília: Fundação Alexandre de Gusmão.

Foracchi, M. (1977). O estudante e a transformação da sociedade brasileira. São Paulo: Biblioteca Universitária.

Gaulejac, V. de (1987). La névrose de classe. Trajectoire sociale et conflits d'identité. Avant-propos de Max Pagès. Paris: Hommes \& Grouos Editeurs.

Gee, J. P. (1991). A linguistic approach to narrative. Journal of Narrative and Life History/Narrative Inquiry, 16(1), 15-39.

Gergen, K. J. (1999/2009). An Invitation to Social construction. Second Edition. London: Sage. 
Houaiss, A. et al. (2001). Dicionário Eletrônico Houaiss da língua portuguesa. Rio de Janeiro: Objetiva.

Instituto Brasileiro de Geografia e Estatística - IBGE (2012). Censo Demográfico 2010: Resultados gerais da amostra. Comunicação Social 27 de abril de 2012. Disponível em: Acesso em 02/05/2012.

Instituto Brasileiro de Geografia e Estatística - IBGE (2015). Pesquisa Mensal de Emprego, Março de 2015. Disponível em: http://www.ibge.gov.br/home/estatistica/indicadores/trabalhoe rendimento/pme_nova/pmecr_201503.shtm

Marandola Jr, Eduardo, \& Dal Gallo, Priscila Marchiori (2010). Ser migrante: implicações territoriais e existenciais da migração. Revista Brasileira de Estudos da População, 27(2), 407-424.

Martes, A. C. B. (2001). Emigração Brasileira: formação de mercados de consumo de produtos brasileiros no exterior. RAE Light, 8(1), 8-12, Jan./Mar.

Ministério das Relações Exteriores - MRE (2011). Brasileiros no Mundo: Estimativas. Terceira Edição Junho de 2011. http://www.brasileirosnomundo.itamaraty.gov.br. Acesso em 24/01/2012. Departamento Consular e de Brasileiros no Exterior. Esplanada dos Ministérios.

Moreno Fuentes, F. J, \& Ferreira, S. de F. (2013). Inmigración, sanidad, crisis económica y politización de la inmigración en España. REMHU: Revista Interdisciplinar da Mobilidade Humana, 21(40), 27-47.

Moya, J. S. \& Escudero, N. A. (2005). Trayectorias laborales, Desempleo y Ciudadanía: el caso de Viña Del Mar. Ultima décad., 13(22), 111-136.

Nobre Lima, L. I. G. F. (2009). Estórias e projetos de vida de adolescentes institucionalizados. Tese de doutorado, Programa de Pós-Graduação em Psicologia, Faculdade de Psicologia e Ciências da Educação, Universidade de Coimbra.

Ornellas, L. P. G. (2015). "São só dois lados da mesma viagem, o trem que chega é o mesmo trem da partida": trajetórias laborais de brasileiros/as retornados/as da Europa Ocidental. Tese de doutorado, Programa de Pós-Graduação em Psicologia, Universidade Federal de Santa Catarina, Florianópolis, SC.

Patarra, N. L. (2005). Migrações internacionais de e para o Brasil contemporâneo: volumes, fluxos, significados e políticas. São Paulo em Perspectiva, 19(3), 23-33.

Pereira, S. \& Siqueira, S. (2013). Migração, retorno e circularidade: evidência da Europa e Estados Unidos. REMHU: Revista Interdisciplinar da Mobilidade Humana, 41(0), 117-138.

Póvoa Neto, H. (2012). Migração: processo espontâneo é criminalizado. Entrevista IHU On-Line por telefone. Quarta, 16 de maio de 2012. Acesso em 17/04/2014. No site: 
http://www.ihu.unisinos.br/entrevistas/509050-migracaoprocesso-espontaneo-e-criminalizado-entrevista-especial-comhelion-povoa-neto

Riessman, C. K. (2008). Narrative Methods for the human Sciences. United States of America: Sage Publications.

Sacconi, L. A. (2011). Nossa Gramática Completa Sacconi: teoria e prática. (31a. ed. rev.) São Paulo: Nova Geração.

Sayad, A. (1998). A imigração ou os paradoxos da alteridade. Tradução Cristina Murachco. São Paulo: Editora da Universidade de São Paulo.

Sayad, A. (2000). O retorno: elemento constitutivo da condição do imigrante. Revista Travessia. Número especial, Janeiro, 3-32.

Schreurs, B., Van Emmerik, H.ty, De Cuyper, N., Notelaers, G., \& De Witte, H. (2011). Job demands-resources and early retirement intention: Differences between blue and white-collar workers. Economic and Industrial Democracy, 32 (1), 47-68.

Silva, L. da (2009). Migrações internacionais e mundos do trabalho: Brasileiros em Portugal e na Espanha (1986-2008). Tese de doutorado, Programa de Pós-Graduação em História, Universidade Federal de Santa Catarina, Florianópolis, SC.

Siqueira, Sueli (2009). Sonhos, sucesso e frustrações na emigração de retorno: Brasil/Estados Unidos. Coleção Trabalho \& Sociedade. Belo Horizonte, MG: Argvmentvm.

Tolfo, S. R., Coutinho, M. C., Baasch, D., \& Cugnier, J. S. (2011). Sentidos y significados del trabajo: un análisis en base a diferentes perspectivas teórico-epistemológicas en Psicología. Universitas Psychológica, 10(1), 19-32

United Nation (1998). Department of Economic and Social Affairs Statistics Division Statistical Papers Series M, No. 58, Rev. 1. Recommendations on Statistics of International Migration Revision 1 United New York. Recuperado de http://unstats.un.org/unsd/publication/SeriesM/SeriesM_58rev1 e.pdf.

Vainer, C. B. (2007). Migração e mobilidade na crise contemporânea da modernização. In Coletânea de textos do Simpósio Internacional: Migração: nação, lugar dinâmicas territoriais. (pp. 11-30). São Paulo: Associação Editorial Humanitas.

\section{Endereço para correspondência \\ Laila Priscila Graf Ornellas}

Universidade Federal de Santa Catarina - UFSC

NETCOS- Núcleo de Estudos do Trabalho e Constituição do Sujeito

Centro de Filosofia e Ciências Humanas

Campus Universitário, Sala 14B, Trindade, CEP 88040-900, Florianópolis - SC, Brasil

Endereço eletrônico: lailagraf@gmail.com

\section{Maria Chalfin Coutinho}


Universidade Federal de Santa Catarina - UFSC

NETCOS- Núcleo de Estudos do Trabalho e Constituição do Sujeito

Centro de Filosofia e Ciências Humanas

Campus Universitário, Sala 14B, Trindade, CEP 88040-900, Florianópolis - SC, Brasil

Endereço eletrônico: maria.chalfin@ufsc.br

Recebido em: 19/11/2015

Reformulado em: 04/08/2016

Aceito em: 23/10/2016

\section{Notas}

* Mestre e Doutora em Psicologia pela Universidade Federal de Santa Catarina.

** Doutora em Ciências Sociais pela Unicamp, Professora do Departamento e do Programa de Pós-Graduação em Psicologia da Universidade Federal de Santa Catarina, Bolsista Produtividade do CNPq.

1 Empregamos o termo "migração" para nos referir ao processo migratório em geral, e usamos "imigração" ou "imigrante" para nos referir tanto às pessoas que vieram ao Brasil na imigração colonial como aos novos imigrantes que entram no país, como também os brasileiros/as que deixaram o país e foram residir no exterior. Os "emigrantes" são aqueles que saíram dos seus países. Silva (2009) também propôs distinção semelhante a essas.

2 O termo "retorno" aqui é frequentemente empregado com aspas, pois, conforme Sayad (2000) e Sayad (1998), não existe um verdadeiro retorno. Sendo assim, as aspas são usadas especialmente para evidenciar a contradição presente nesse termo.

${ }^{3} \mathrm{O}$ estudo longitudinal e biográfico foi desenvolvido na pesquisa original (autora, 2015) e não foi abarcado aqui devido aos limites desta comunicação.

${ }^{4}$ O contexto socioeconômico brasileiro altera-se novamente em meados de 2015, observando a elevação das taxas de desemprego (IBGE, 2015).

${ }^{5}$ Aqui efetuamos uma distinção entre os termos história e estória. Para nós, esses possuem significações diferentes. O termo história é empregado quando se refere a algum momento social e histórico ocorrido no passado, com o compromisso de que o fato realmente ocorreu (Sacconi, 2011; Houaiss et al, 2001). No entanto, empregamos o termo estória para indicar quando as pessoas relatam suas vivências e constroem a coerência sobre as suas falas, mas sem necessariamente estar atrelada ao fato, pois elas podem ampliar alguns aspectos ou enfatizar outros. Esse entendimento pode ser visto em Nobre Lima (2009), pois, segundo essa autora: "[...] as estórias de vida baseiam-se em factos biográficos, mas não se confundem com a história de vida. Quer isto significar que o indivíduo seleciona os fatos vividos em função do significado que Ihes atribui e trabalha em imaginação o seu passado e o seu futuro para construir uma estória que faça sentido a si próprio e à sua audiência" (grifos nossos, p. 19).

${ }^{6}$ Salientamos que esses nomes são fictício. 